\title{
Network effects and infrastructure productivity in developing countries
}

Citation for published version (APA):

Candelon, B., Colletaz, G., \& Hurlin, C. (2009). Network effects and infrastructure productivity in developing countries. METEOR, Maastricht University School of Business and Economics. METEOR Research Memorandum No. 050 https://doi.org/10.26481/umamet.2009050

Document status and date:

Published: 01/01/2009

DOI:

10.26481/umamet.2009050

Document Version:

Publisher's PDF, also known as Version of record

\section{Please check the document version of this publication:}

- A submitted manuscript is the version of the article upon submission and before peer-review. There can be important differences between the submitted version and the official published version of record.

People interested in the research are advised to contact the author for the final version of the publication, or visit the DOI to the publisher's website.

- The final author version and the galley proof are versions of the publication after peer review.

- The final published version features the final layout of the paper including the volume, issue and page numbers.

Link to publication

\footnotetext{
General rights rights.

- You may freely distribute the URL identifying the publication in the public portal. please follow below link for the End User Agreement:

www.umlib.nl/taverne-license

Take down policy

If you believe that this document breaches copyright please contact us at:

repository@maastrichtuniversity.nl

providing details and we will investigate your claim.
}

Copyright and moral rights for the publications made accessible in the public portal are retained by the authors and/or other copyright owners and it is a condition of accessing publications that users recognise and abide by the legal requirements associated with these

- Users may download and print one copy of any publication from the public portal for the purpose of private study or research.

- You may not further distribute the material or use it for any profit-making activity or commercial gain

If the publication is distributed under the terms of Article $25 \mathrm{fa}$ of the Dutch Copyright Act, indicated by the "Taverne" license above, 
Bertrand Candelon, Gilbert Colletaz, Christophe Hurlin

Network Effects and I nfrastructure Productivity in Developing

Countries

$\mathrm{RM} / 09 / 050$

\section{METEOR}

Maastricht University School of Business and Economics

Maastricht Research School of Economics

of Technology and Organization

\section{PO. Box 616}

NL - 6200 MD Maastricht

The Netherlands 


\title{
Network Effects and Infrastructure Productivity in Developing Countries *
}

\author{
Bertrand Candelon† Gilbert Colletaz ${ }^{\ddagger}$ and Christophe Hurlin ${ }^{\S}$
}

September 2009

\begin{abstract}
This paper proposes to investigate the threshold effects of the productivity of infrastructure investment in developing countries within a panel data framework. Various specifications of an augmented production function that allow for endogenous thresholds are considered. The overwhelming outcome is the presence of strong threshold effects in the relationship between output and private and public inputs. Whatever the transition mechanism used, the testing procedures lead to strong rejection of the linearity of this relationship. In particular, the productivity of infrastructure investment generally exhibits some network effects. When the available stock of infrastructure is very low, investment in this sector has the same productivity as non-infrastructure investment. On the contrary, when a minimum network is available, the marginal productivity of infrastructure investment is generally largely greater than the productivity of other investments. Finally, when the main network is achieved, its marginal productivity becomes similar to the productivity of other investment.
\end{abstract}

- Key Words : Infrastructure, Threshold Panel Regression Models.

- J.E.L Classification : C82, E22, E62.

\footnotetext{
${ }^{*}$ We would like to thank Santiago Herrera for his support and his comments on a previous version of this work (World Bank Policy Research Working Paper 3808). We also thank Mohamed Belkir for his comments. All the codes (developed with Matlab 7.1 and WinRats) are available on the website of the authors.

${ }^{\dagger}$ Corresponding author. Maastricht University, Department of Economics. The Netherlands. Email: b.candelon@maastrichtuniversity.nl.

${ }^{\ddagger}$ University of Orléans, LEO (UMR CNRS 6221).

${ }^{\S}$ University of Orléans, LEO (UMR CNRS 6221).
} 


\section{Introduction}

Most public investments, particularly public investments in infrastructure, are generally devoted to the construction of networks. This is clear when we consider public investments in roads, railways, telecommunications, electricity, water, and sewer systems, and is also true when we consider residential public investments in educational buildings. In this case, as noted by Romp and De Haan (2005), the internal composition of stock matters, since the marginal productivity of one link depends on the capacity and configuration of all of the links in the network. Hence, using measures of the total stock may allow the estimation of the average marginal product of roads in the past; however, these estimates may not be appropriate for evaluating the marginal product of additional roads today. This argument has been used by Fernald (1999) to assess the link between public capital and productivity in the road sector in the United States. His evaluation based on industry data does not support the idea that public investment offers a continuing and neglected route to prosperity. More precisely, his estimations do not allow the rejection of the hypothesis that roads now offer a normal (or even zero) rate of return. He concludes that "the data seem consistent with a story in which the massive road-building projects of the 1950's and 1960's offered a one-time boost to the level of productivity, rather than a path to continuing rapid growth in productivity. This conclusion - that roads were exceptionally productive before 1973, but not exceptionally productive at the margin - is consistent with the simple network argument. In particular, building an interstate network might be very productive, whereas building a second network may not" (Fernald, 1999, page 621). This network character is likely to be generalised to the primary components of public investments not only in the United States, but also in most developing countries.

What is the main implication of this network dimension for the evaluation of infrastructure productivity? It clearly implies that the relationship between the output and the level of public capital stock (or infrastructure stock) is strongly non-linear. 
More precisely, this relationship may depend on the level of infrastructure actually available and may be represented by a threshold model. For instance, one might suggest, as Fernald (1999) does, that the construction of a network substantially boosts total factor productivity and output, but that when the construction of a network is completed, infrastructure investments may be not be exceptionally productive at the margin. Thus, the marginal productivity of these investments is not identical given the level of stock actually available in the country: a low level of infrastructure stock (relative to the population or workforce, for instance) indicates that the construction of the network is not complete and implies high productivity; likewise, a high level of stocks implies null or low marginal productivity if the network is built. These properties clearly correspond to the definition of a threshold regression model: "threshold regression models specify that individual observations can be divided into classes based on the value of an observed variable" (Hansen, 1999, page 346).

In this paper, we propose to use these threshold regression models in order to take into account this original dimension in the estimation of rates of return on public capital stocks, i.e. the potential presence of threshold effects. Applying the so-called production function approach introduced by Aschauer (1989), we consider various specifications of public capital stock-augmented production functions. So far, we have used the terms of public capital and infrastructure; however, the notion of infrastructure does not fully correspond to the concept of public sector investment expenditure. This distinction is particularly important in interpreting threshold effects. Indeed, it would be naïve to directly interpret the threshold effects related to the productivity of public capital as network effects: public investments are so heterogeneous that the level of public investments or public capital stocks cannot be used to reveal information on the completion of the main infrastructure networks. For this reason, in this paper, we only consider the threshold effects of the productivity of infrastructure investments.

More precisely, we propose to re-evaluate the marginal productivity of infrastructure stocks using threshold regression models, in which the threshold variable may be defined as the level of the infrastructure stock actually available. The main concern with these models is that they require a significant number of observations to be estimated because they depend on a significant number of parameters. This concern is particularly 
relevant in our context, since the time dimension of the series of infrastructure stocks is generally not sufficient to estimate such models, even if we consider only two regimes ${ }^{1}$. One solution is to use panel data, as is generally done in the literature devoted to linear representations of the productivity of infrastructure. In a seminal paper, Hansen (1999) proposed the first procedure for estimating and testing threshold effects in nondynamic panels. His Panel Threshold Regression (PTR) model allows for the dividing of individual observations into classes according to an observable variable. In this case, the time series and cross sections are used in order to identify the regimes. Based on his procedure, it is then possible to test and to estimate the threshold effects for the marginal productivity of infrastructure in a panel of countries without assuming the homogeneity of the aggregated production function. This model assumes a transition from one regime to another based on the value of a threshold variable, for instance, the infrastructure stock: in a model with two regimes, if the threshold variable is below a certain value, called the threshold parameter, productivity is defined by one model, whereas it is defined by another model if the threshold variable exceeds the threshold parameter.

It is important to note that the existence of threshold effects related to the productivity of infrastructure is compatible with the three major criticisms of the linear specifications of the production function in the vast body of literature devoted to this topic (see Gramlich, 1994; Sturm, 1998; or Romp and De Haan, 2005 for a survey). Indeed, with reference to estimating the rates of return on infrastructure (or public capital) with an augmented production function in a panel, three major problems are generally raised. The first is potential reverse causation. If public investments depend on income, this implies a feedback effect from income to the capital stocks. Consequently, the linear regression of the output on public and private factors does not allow one to directly identify the parameters of the production function. Several solutions have been proposed in the literature in order to take into account this problem of reverse causation. Canning (1999) and Canning and Bennathan (2000) argue that the

\footnotetext{
${ }^{1}$ This is the main reason why these models have not been used even in the analysis of OECD countries. To the best of our knowledge, no study devoted to the productivity of public capital and based on threshold models has yet been proposed.
} 
use of panel estimates under various assumptions allows one to identify the long-run production function relationship. Another solution consists of estimating a system of simultaneous equations: one equation for the production function and another equation for the relationship between the public capital stock and production (Demetriades and Mamuneas, 2000). Finally, the reverse causation problem can be tackled using an instrumental variable approach or a generalised method of moments. This occurs, for instance, in the work of Finn (1993), Holtz-Eakin (1994), Baltagi and Pinnoi (1995), Ai and Cassou (1995), Otto and Voss (1998), and more recently, in Calderon and Serven (2004). however, the reverse causation issue can also be interpreted as a consequence of threshold effects. For instance, let us assume that the true data generation process of marginal productivity is a threshold model, as suggested by Fernald (1999). Infrastructure investments enhance the output until the completion of the main networks, and once they are finished, it is mainly the output that causes changes in the infrastructure capital stocks. In this case, the use of a linear specification leads to an estimated correlation that takes into account both the influence of the infrastructure on the output in the first period and the influence of the output on the infrastructure stock in the second period. In contrast, the use of a threshold model based on the value of the capital stock per capita, for instance, makes it possible to identify the influence of infrastructure on the total factor productivity in the first period.

The second major problem raised in the literature is the non-stationarity and the non-cointegration of the data used in the augmented production function (Tatom, 1991; Sturm and Haan, 1995; Crowder and Himarios, 1997). In a time series, it is generally recognised that unit root tests based on linear specifications (ADF, KPSS etc.) are likely to indicate the non-stationarity of series when the true data generation model is a threshold model (SETAR, STAR etc.). Even if similar studies have not been done with panel unit root tests, it is obvious that the first-generation tests, like Im, Pesaran, and Shin's test (2003) based on an average of individual ADF statistics, are likely to yield the same kind of results.

The last major problem, which is specific to the panel estimates, is the poten- 
tial heterogeneity of the parameters of the production function and, more particularly, the heterogeneity of the elasticities of output with respect to infrastructure (or public capital) stocks. Often, both in cross-section and in panel data studies, it is assumed that the parameters are common across countries; however, this assumption may raise significant issues when the countries in the panel are very different, as is the case in our sample of developing countries. Consequently, the studies based on a production approach are generally based on specifications with fixed or random individual effects (Evans and Karras, 1994; Holtz-Eakin; 1994); however, to the best of our knowledge, few studies in the literature allow the other parameter of the augmented production function to vary across countries ${ }^{2}$. Canning (1999) and Canning and Bennathan (2000) investigate the possible heterogeneity of the production function by splitting their sample into two groups of countries based on their levels of income per worker in a baseline year. Their results based on a Cobb-Douglas production function show that the coefficients of the infrastructure terms in poorer countries are very small, and statistically insignificant, but remain large and significant in richer countries. They conclude that "infrastructure in poorer countries appears to have the same effectiveness in raising output as other types of physical capital, whereas in richer countries, has a greater effectiveness than other types of capital" (Canning and Bennathan, 2000, page 13). In this case, the cross-country heterogeneity of production technology can be interpreted as the consequence of threshold effects. The idea is very simple: at each date in the threshold model, the countries are divided into a small number of classes with the same elasticities according to an observable variable. This threshold variable can be defined, for instance, as the level of income per capita, according to the decomposition used by Canning and Bennathan (2000); however, the main difference is that the heterogeneity of the production technology is then endogenously determined by the threshold model and not specified ex-ante by splitting the sample into two or three groups of countries. In summary, the existence of non-linearity, and more specifically, of threshold effects in the productivity of public capital and infrastructure stocks is largely compatible with the main empirical observations made in the literature.

\footnotetext{
${ }^{2}$ With random coefficient models, for instance (Swamy, 1970).
} 
This paper is organised as follows. In the second section, we motivate the presence of threshold effects related to the productivity of infrastructure in road, electricity, telephone, and railways sectors. In the third section, the data are presented. We report the results obtained in linear specifications, and hence create a benchmark model. In section four, we test the hypothesis of network effects and the influence of income heterogeneity on production technology. A procedure that tackles possible endogeneity biases is proposed in Section 5. Similarly, the possibility of a multi-threshold model is investigated in Section 6. Section 7 proposes the association of the threshold with income heterogeneity. The last section concludes.

\section{The Productivity of Infrastructure: toward a Threshold Specification}

The basis of our empirical approach is exactly the same as that used by many authors since the seminal paper of Aschauer (1989) and, more recently, by Canning (1999), Canning and Bennathan (2000), and Calderon and Serven (2004) for developing countries. It consists of estimating the parameters of an infrastructure augmented production function. We follow the literature by adopting a Cobb-Douglas specification of the production function. If we consider a country $i=1, . ., N$ at a time $t=1, ., T$, we assume that

$$
Y_{i t}=A_{i} K_{i t}^{\alpha} H_{i t}^{\beta} X_{i t}^{\gamma} L_{i t}^{1-\alpha-\beta-\gamma} V_{i t},
$$

where $Y_{i t}$ is the aggregate added value, $K_{i t}$ is physical capital, $H_{i t}$ is human capital, $X_{i t}$ is infrastructure, and $V_{i t}$ is an error term. As usual in this kind of literature, we assume that the infrastructure services are proportional to the infrastructure capital stock. Moreover, we assume constant returns to scale, so that the sum of the exponents is one. Dividing through by $L_{i t}$ and taking logarithms, we have the following expression:

$$
y_{i t}=a_{i}+\alpha k_{i t}+\beta h_{i t}+\gamma x_{i t}+v_{i t},
$$

where $v_{i t}=\log \left(V_{i t}\right)$ and capital stocks and output are in terms of log per worker. The individual fixed effects $a_{i}$ capture all timeless components of total factor productivity. It is also possible to include some time effects in this linear specification to capture 
the common factors in the total factor productivity. The equation (2) corresponds exactly to the model estimated by Canning (1999), Canning and Bennathan (2000), and Calderon and Serven (2004). As noted by these authors, it is difficult to directly interpret the parameters of equation (2) because infrastructure capital appears twice, once on its own, but also as a part of aggregate capital $K_{i t}$. Consequently, the parameter $\gamma$ cannot be interpreted as the infrastructure elasticity. More precisely, Canning (1999) shows "that in this case the parameter $\gamma$ captures the extent to which the productivity of infrastructure exceeds (if $\gamma>0$ ) or falls short (if $\gamma<0$ ) of the productivity of non-infrastructure capital" (Calderon and Serven, 2004, page 98). Thus, the elasticity of output with respect to infrastructure is not constant and depends on the ratio of capital stocks; however, as noted by Calderon and Serven (2004), because infrastructure stocks typically account for relatively small portions of overall capital stock, the difference between the genuine elasticity evaluated around the sample mean and the naïve estimate $\gamma$ should be fairly modest in practice.

As was previously mentioned, in this study, we propose to consider exactly the same framework as that studied in the aforementioned literature, except for the fact that we introduce non-linearity in order to test and to match the network dimension of infrastructure. In order to take into account this specificity of infrastructure, a solution was to adopt a Panel Threshold Regression (PTR) model similar to that proposed by Hansen (1999):

$$
y_{i t}= \begin{cases}a_{i}+\alpha_{1} k_{i t}+\beta_{1} h_{i t}+\gamma_{1} x_{i t}+\varepsilon_{i t} & \text { if } q_{i t} \leq \lambda \\ a_{i}+\alpha_{2} k_{i t}+\beta_{2} h_{i t}+\gamma_{2} x_{i t}+\varepsilon_{i t} & \text { if } q_{i t}>\lambda .\end{cases}
$$

where $q_{i t}$ denotes a threshold variable and $\lambda$ denotes a threshold parameter. This model can be rewritten as

$$
y_{i t}=a_{i}+\delta_{1}^{\prime} W_{i t} \mathbb{I}_{\left(q_{i t} \leq \lambda\right)}+\delta_{2}^{\prime} W_{i t} \mathbb{I}_{\left(q_{i t}>\lambda\right)}+\varepsilon_{i t},
$$

where $\delta_{j}=\left(\alpha_{j} \beta_{j} \gamma_{j}\right)^{\prime}$ for $j=1,2$ and $W_{i t}=\left(k_{i t} h_{i t} x_{i t}\right)^{\prime}$, and where $\mathbb{I}_{(.)}$is the indicator function. The error $\varepsilon_{i t}$ is assumed to be independent and identically distributed with a zero mean and finite variance $\sigma^{2}$. Two remarks must be made here. In this model, the observations are divided into two regimes depending on whether the threshold variable 
$q_{i t}$ is smaller or larger than the threshold parameter $\lambda$. No constraint is imposed on the choice of the threshold variable except for the fact that it cannot be the contemporaneous endogenous variable and cannot be time-independent. We will further discuss the choice of this threshold variable. The second remark is that in Hansen (1999), the individual effects $a_{i}$ are not different in the two regimes. It would be possible to consider a constant or $N$ individual constant specific to each regime, but this would greatly increase the number of parameters of the model. Thus, the regimes are distinguished by their differing elasticities, $\delta_{1}$ and $\delta_{2}$. The elasticities of output with respect to the three inputs (total capital, Infrastructure, and human capital) are assumed to be regime-dependent.

Naturally, a general specification can be studied with more than two regimes. The procedure of estimation proposed by Hansen allows one to consider a model with $K$ regimes; however, in this study, we limit our investigation to models with at most four regimes (three threshold parameters). For example, threshold models with three and four regimes (two and three threshold parameters, respectively) take the form

$$
\begin{gathered}
y_{i t}=a_{i}+\delta_{1}^{\prime} W_{i t} \mathbb{I}_{\left(q_{i t} \leq \lambda_{1}\right)}+\delta_{2}^{\prime} W_{i t} \mathbb{I}_{\left(\lambda_{1}<q_{i t} \leq \lambda_{2}\right)}+\delta_{3}^{\prime} W_{i t} \mathbb{I}_{\left(q_{i t}>\lambda_{2}\right)}+\varepsilon_{i t}, \\
y_{i t}=a_{i}+\delta_{1}^{\prime} W_{i t} \mathbb{I}_{\left(q_{i t} \leq \lambda_{1}\right)}+\delta_{2}^{\prime} W_{i t} \mathbb{I}_{\left(\lambda_{1}<q_{i t} \leq \lambda_{2}\right)} \\
+\delta_{3}^{\prime} W_{i t} \mathbb{I}_{\left(\lambda_{2}<q_{i t} \leq \lambda_{3}\right)}+\delta_{4}^{\prime} W_{i t} \mathbb{I}_{\left(q_{i t}>\lambda_{3}\right)}+\varepsilon_{i t},
\end{gathered}
$$

where the threshold parameters $\lambda_{j}$ are sorted, $\lambda_{1}<. .<\lambda_{K}$. In all the cases, the parameters $\delta_{j}, j=1, \ldots K$ are estimated according to the same simple least square sequential procedure as that used for the standard STAR or SETAR models for times series. If we consider the single threshold model (equation 20) for a given value of the threshold parameter $\lambda$, the slope coefficients $\delta_{1}$ and $\delta_{2}$ can be estimated by OLS. Let us denote $\widehat{\delta}_{1}(\lambda)$ and $\widehat{\delta}_{2}(\lambda)$, as the corresponding estimates. Thus, conditional to a value of $\lambda$, it is possible to compute the sum of squared errors, denoted as $S_{1}(\lambda)$.

$$
S_{1}(\lambda)=\sum_{i=1}^{N} \sum_{t=1}^{T} \widehat{\varepsilon}_{i t}^{2}(\lambda) .
$$


The threshold parameter $\lambda$ is then estimated by minimising the sum of squared $S_{1}(\lambda)$.

$$
\widehat{\lambda}=\underset{\lambda \in \Lambda}{\operatorname{ArgMin}} S_{1}(\lambda) .
$$

Since this sum of squared residuals depends on $\lambda$ only through the indicator function, it is a step function with at most $N T$ steps, with the steps occurring at distinct values of $q_{i t}$ in the sample. Thus, the minimisation problem can be reduced to searching over values of $\lambda$ that equal at the most distinct values of $q_{i t}[\mathrm{ED} 1]$ in the sample. Given the value of the estimate $\hat{\lambda}$, it is then possible to make an estimate of the elasticities in the regimes, i.e. $\widehat{\delta}_{1}(\widehat{\lambda})$ and $\widehat{\delta}_{2}(\widehat{\lambda})$, and the estimates of individual effects $\widehat{a}_{i}$. As was stressed in Hansen (1999), it is undesirable for a threshold $\hat{\lambda}$ to be selected that sorts too few observations into one or another regime. That is why we consider an optimisation domain $\Lambda$ that assures that a minimal percentage of the observations lie in each regime. More precisely, the minimisation program (8) can be solved by a direct search over the values of $\gamma$ that equal the most $N T$ distinct values of the threshold variable $q_{i t}$ in the sample. If we sort the $N T$ distinct values of the observations on $q_{i t}$, the previous constraint implies the elimination of the smallest and largest values. The remaining values constitute the set $\Lambda$ of values of $\lambda$ that can be searched for $\widehat{\lambda}$. In our application, the smallest and largest $5 \%$ values are eliminated. The same kind of procedure is used for models with three or four regimes. Thus, for each model, at least $5 \%$ of the total of the NT observations is available to estimate the elasticities in each regime.

There are two main problems with this threshold model. The first has to do with testing the number of regimes or testing the threshold specification. The second issue involves the choosing of the threshold variable. Let us assume that the threshold variable is known. If the threshold effect is tested to be statically significant in the model with two regimes (equation 20), the null hypothesis is $H_{0}: \delta_{1}=\delta_{2}$. This null hypothesis corresponds to the hypothesis that there is no threshold effect. Under $H_{0}$, the model is then equivalent to a linear model (equation 2). This hypothesis could be tested using a standard test. If we note $S_{0}$ as the sum of squares of the linear model, 
the approximate likelihood ratio test of $H_{0}$ is based on the following:

$$
F_{1}=\frac{S_{0}-S_{1}(\widehat{\lambda})}{\widehat{\sigma}^{2}}
$$

where $\widehat{\sigma}^{2}$ denotes a convergent estimate of $\sigma^{2}$. The main problem is that under the null, the threshold parameter $\lambda$ is not identified. Consequently, the asymptotic distribution of $F_{1}$ is not standard and, in particular, does not correspond to a chi-squared distribution. This issue has been largely studied in literature devoted to threshold models, notably since the seminal paper by Hansen (1996). One solution is to use bootstrapping simulation to determine the asymptotic distribution of the statistic $F_{1}$. Hansen (1996) shows that using a bootstrap procedure to attain the asymptotic distribution works, so that the p-values constructed from the bootstrap are asymptotically valid. As proposed by Hansen (1999) in the context of panel models, we use bootstrap simulations to compute the critical values of the distribution of the statistics of the tests on the number of thresholds.

The same kind of procedure can be applied to general models (equations 5 or 6 ) in order to determine the number of thresholds. If the p-value associated with $F_{1}$ leads us to rejects the linear hypothesis, we can then discriminate between one and two thresholds. A likelihood ratio test of one threshold versus two thresholds is based on the statistic

$$
F_{2}=\frac{S_{1}(\widehat{\lambda})-S_{2}\left(\widehat{\lambda}_{1}, \widehat{\lambda}_{2}\right)}{\widehat{\sigma}^{2}},
$$

where $\widehat{\lambda}_{1}$ and $\widehat{\lambda}_{2}$ denote the threshold estimates of the model with three regimes (equation 5$)$, and $S_{2}\left(\widehat{\lambda}_{1}, \hat{\lambda}_{2}\right)$ denotes the corresponding residual sum of squares. The onethreshold hypothesis is rejected in favour of the two-threshold hypothesis if $F_{2}$ is larger than the critical value of the non-simulated distribution. The corresponding asymptotic p-value can be approximated via bootstrap simulations (Hansen, 1999). If the model with two thresholds (three regimes) is accepted, we propose to test the two-threshold (three-regime) hypothesis against the alternative of three thresholds (four regimes). The corresponding likelihood ratio statistic, denoted $F_{3 .}$, is defined as:

$$
F_{3}=\frac{S_{2}\left(\widehat{\lambda}_{1}, \widehat{\lambda}_{2}\right)-S_{3}\left(\widehat{\lambda}_{1}, \widehat{\lambda}_{2}, \widehat{\lambda}_{3}\right)}{\widehat{\sigma}^{2}},
$$


where $S_{3}\left(\widehat{\lambda}_{1}, \widehat{\lambda}_{2}, \widehat{\lambda}_{3}\right)$ denotes the residual sum of squares of the model with four regimes and three threshold parameters. In models with $m+1>2$ regimes, the estimates of the $m$ threshold parameters can be done sequentially by using the estimated threshold parameters obtained in the model with $m$ regimes, as suggested by Bai and Perron (1998) in the context of multiple change-point models. In this paper, we limit our analysis to a model with a maximum of four regimes given the computational cost of such models. Thus, a sequential procedure based on $F_{1}, F_{2}$ and $F_{3}$ allows us to determine the number of regimes ${ }^{3}$.

The second issue consists of determining the threshold variable. Few technical constraints are imposed on the choice of the threshold variable. The only constraint is that the threshold variable cannot be time-invariant. Therefore, this choice is primarily an economic issue. If we want to assess the idea that infrastructure investments have a network character, this implies that the threshold variable should be an indicator of the completion of the network. From this perspective, a natural candidate for the threshold variable is the existing level of available infrastructure. According to Fernald (1999), a low level of capital (relative to the population or to the workforce, for instance) indicates that the construction of the network is not complete and may imply high stock productivity, whereas a high level of stocks may imply null or low marginal productivity if the network is built. Two choices are then possible:

the threshold variable can be defined as the level of infrastructure stock or as the level of infrastructure stock per worker (or per capita). The second variable allows us to avoid the scale effects in the network. Thus, our first specification is based on the following threshold variable:

$$
\text { Model A : } q_{i t}=x_{i t} \text {. }
$$

This model can be extended in order to include more than one variable in the threshold function. If we define $y_{i t}^{(1)}$ as the road infrastructure variable, $y_{i t}^{(2)}$ as the telephone infrastructure variable, $y_{i t}^{(3)}$ as the electricity infrastructure variable, and $y_{i t}^{(4)}$ as the rail infrastructure variable, the third model will take the following form:

\footnotetext{
${ }^{3}$ The code for the estimation and inference procedures were written using Matlab and Rats, and are available upon request.
} 


$$
\text { Model A1: } \quad q_{i t}=\sum_{j=1}^{4} y_{i, t-1}^{(j)} .
$$

Another solution regarding the threshold variable would consist of using the lagged level of GDP per worker, i.e. $q_{i t}=y_{i, t-1}$. It is necessary to use the lagged value of $y_{i t}$ in order to avoid simultaneity, since this variable is the endogenous variable of our regressions. This specification corresponds to the heterogeneity between "rich" and "poor "countries, as suggested by Canning and Bennathan (2000); however, contrary to Canning and Bennathan, our heterogeneity is endogenous in the sense that it is the threshold variable $y_{i, t-1}$ (and the threshold parameters $\lambda_{j}$ that determines the list of countries included in the different regimes of productivity. Besides, in our specification, a country with low productivity (that belongs to regime 1, for instance) in the beginning of the period can enjoy a medium or high level of productivity at the end of the sample period (i.e. can belong to regime 2 or 3 ). Therefore, we consider a second model with the following:

$$
\text { Model B: } \quad q_{i t}=y_{i, t-1} \text {. }
$$

\section{Data and Linear Models of Productivity}

We consider the same data as those used by Canning (1999) and Canning and Bennathan (2000). For output, we use purchasing power parity ${ }^{4}$ GDP per worker (chain index). In both studies, physical capital stocks are constructed using a perpetual inventory method. The initial stock is obtained by assuming a capital-output ratio of $3 \%$ in the base year. The flows of investments are taken from the Penn World Tables 6.00. Like Canning, we assume a constant depreciation rate of $7 \%$ for private capital. Canning shows that his results are robust to variations in the initial choice of capitaloutput ratio and the depreciation rate. Finally, human capital per worker is taken to be the average years of schooling of the workforce. Because of data availability constraints, the average years of schooling of the workforce is approximated here using the average years of schooling of the total population aged 15 and above ${ }^{5}$, from Barro and

\footnotetext{
${ }^{4}$ It is important to note that in the Penn World Tables, "real" means "PPP converted" instead of "in constant price".

${ }^{5}$ Variable code: TYR15, Barro and Lee (2000), "International Data on Educational Attainment: Updates and Implications", Harvard University, February 2000.
} 
Lee (2000). Since these human capital data are available only every five years, Canning suggests the use of interpolation to yield annual data.

We use four infrastructure capital stock variables: the number of telephones, kilowatts of electricity-generating capacity, and the lengths of paved roads and railways lines, both expressed in kilometers. The infrastructure figures are the processed data from Canning (1998). The corresponding maximal sample is 1950-1995. As stated by Canning, these physical measures do not reflect the quality differences in infrastructure across countries and over time. The effectiveness of infrastructure may depend on its quality, both initially and in terms of maintenance; however, as noted by Canning, a simple fixed effect specification allows us to capture a part of these cross-country quality differences, more precisely, the part that is constant over time. Consequently, in all of our models, individual fixed effects are introduced.

The estimation of a threshold model requires the use of a balanced panel. For each specification, i.e. for each type of infrastructure, we select countries (among a total of 146 countries) for which we have a complete data set for the relevant variables over the longest period. The period of estimation is chosen in order to maximise the total number of observations. That is why, as in previous studies, the composition of our panel varies with the type of infrastructure considered. For each specification, the sample used and the number of countries included are reported in Table 1. The countries can be divided in four groups: low-income countries (LIC), lower-middle-income countries (LMI), upper-middle-income countries (UMI), and high-income countries (HIC). These groups are based on World Bank definitions.

In order to assess the comparability of our data sets to the data sets used in previous studies, we first estimate the augmented production function in linear panel models. As in Calderon and Serven (2004), we propose simple estimators of the equation (2). The results are reported in Table 2. First, we consider a model in which the four infrastructures are simultaneously introduced in the production function. It can be seen that all regressors carry positive coefficients, all significantly different from zero ${ }^{6}$. The

\footnotetext{
${ }^{6}$ We do not report t-ratios based on the long-run auto-covariance matrix, as in Canning (1999).
} 
same qualitative results are obtained when the infrastructure variables are separately introduced (column 2 to 4 ). Our results are not directly comparable to those of Canning (1999) because $(i)$ he considers a specification with lead and lagged explanatory variables in order to obtain consistent estimates of the long-run parameters (Kao and Chiang, 2000), (ii) he considers only three types of infrastructures, and (iii) his panel is not balanced and covers more countries than our data set does; however, we can observe that the values of the various estimated parameters are roughly similar. In our sample, the estimated elasticity of physical capital is slightly greater than that obtained by Canning (0.37) with a panel of 57 countries in a specification with 2 lags and 1 lead; however, it is exactly the same value as those obtained by Canning in a model without leads and lags, and with only physical and human capital stocks as explanatory variables (table 32, page 11, Canning, 1999). Moreover, the estimated parameters $\gamma$ when the infrastructures are introduced one-by-one are similar to those reported by Canning and Bennathan (2000). For instance, the estimated parameter associated with paved roads is 0.07 in our balanced sample of 50 countries, whereas it is equal to 0.083 in the dynamic specification (2 lags, 1 lead) estimated by Canning and Bennathan for a panel of 67 countries. For electricity, our estimated parameter is 0.052 , whereas their estimated parameter is equal to 0.085 and to 0.057 when electricity-generating capacity is introduced simultaneously with the figure for kilometers of paved roads.

Thus, our results for linear models based on the four balanced panels are quite similar to those generally obtained in the literature. Consequently, our country selection procedure can be considered robust in the sense that it does not distort estimates of productivity as compared to those previously reported. Given these balanced panels, we now consider the estimation of the productivity of infrastructures when threshold effects are introduced.

Such corrected t-ratios are not computed in the threshold models, and we choose to report the same t-statistics in linear and non-linear models. Moreover, the t-ratios based on estimated long-run variance with a Bartlett kernel and a common lag truncation parameter of 3 (as in Canning, 1999) give the same qualitative results, wherein even though the values of the t-ratios are smaller than those reported in Table 2. 


\section{Threshold Models and Network Effects (Model A)}

We now consider models in which the threshold variable is defined as the level of one available infrastructure. The aim of this specification is to capture the network effects of the infrastructure in order to estimate robust rates of returns. As was previously mentioned, the first step consists of determining the number of regimes or testing the threshold. Toward that end, we consider the sequential procedure proposed by Hansen (1999). The model is estimated, allowing for sequentially zero, one, two, and three thresholds. For each specification, the tests statistics $F_{1}, F_{2}$, and $F_{3}$, along with their bootstrap p-values, are reported. The results of these tests for Model A, wherein the threshold variable $q_{i t}$ is defined as the infrastructure stock per worker $x_{i t}$, are reported in Table 3.

We find that the test for a single threshold $F_{1}$ is highly significant, with a bootstrap p-value smaller than 0.001 for all of the infrastructure variables considered. A lower value for the $F_{1}$ statistic is obtained for the telecommunications sector, but even in this case, the value of the test statistic is largely below the critical values at standard levels. This constitutes strong evidence that the relationship between output and the considered inputs is non-linear. As was suggested by Fernald (1999) and Gramlich (1994), the network aspect of infrastructure investment encourages strong non-linearity in the productivity of this equipment and these structures. The test for a double threshold $F_{2}$ is also strongly significant, with a bootstrap p-value smaller than 0.001 . The last test for a third threshold $F_{3}$ is also significant, even if in this case, the value of the F-statistic is much less significant than those reported for the models with one or two thresholds. According to Hansen's procedure, it would be necessary to pursue and test for four thresholds and five thresholds etc. until the corresponding F-test was statistically not significant; however, as was previously mentioned, we limit our analysis in this section to a model with at most three threshold parameters and four regimes. This choice is justified by the computational cost of the estimation and inference procedures for panel models with more than four regimes. Additionally, we show that, given the sequential estimation procedure proposed by Hansen, when a supplementary regime is 
introduced, it does not affect (or just slightly affects) the estimates of the other threshold parameters and of the slope parameters in the existing regimes. For instance, if we compare the estimated elasticities (and particularly those of infrastructure) obtained in a model with three regimes (see appendix A1) to the estimated elasticities obtained in a model with four regimes, we will see similar results in the three existing regimes. For all of these reasons, we limit our analysis to a model with three threshold parameters and four regimes in considering the relationship between output and capital stocks.

The estimates of the parameters of the PTR models with four regimes and the corresponding t-statistics based on standard errors corrected for heteroskedasticity are reported in Table 4. Following Model A, the infrastructure stock per worker is the threshold variable. In the electricity sector, the results clearly reflect the network dimension of investments devoted to electricity-generating capacity. Indeed, we observe that when electricity-generating capacity per worker is very low (less than 32909 kilowatts per worker), the investments in this sector have the same productivity as other private investments; the estimated parameter $\gamma$ is not significantly different from zero. On the contrary, when a minimum network is available, the marginal productivity of electricity-generating capacity is significantly greater than the productivity of other investments. When the electricity-generating capacity ranges from 32909 kilowatts per worker to 62536 kilowatts per worker, the estimated parameter $\gamma$ is equal to 0.655 . This value is significantly greater than the values generally obtained in linear specifications in panel models. Recall that in our sample, the estimated parameter $\gamma$ obtained in a linear specification with individual effects and time effects was only equal to 0.05 (see Table 2). This indicates that if we do not take into account the non-linearity of the relationship between infrastructure and output, the productive effect of these investments can be undervalued during the period of building the network. When the network is near completion, i.e. when the capacity per worker ranges from 62536 to 595710 , the marginal productivity of infrastructure is always significantly greater than the productivity of other investments, but the value of the parameter $\gamma$ is smaller than in the previous regime. The estimated parameters fall from 0.665 to 0.135 , which is a value similar to that generally obtained in linear models (Canning, 1999; Calderon and 
Serven, 2004). This decrease in the naïve measure ${ }^{7}$ of the elasticity of infrastructures reflects the progressive maturity of the network and not only a standard argument of decreasing returns, which would only imply a simple constraint on the position of this elasticity with respect to the unity. Finally, when the electricity-generating capacity per worker exceeds 595710 kilowatts per worker, the productivity of investments in this sector becomes similar to that obtained in linear models; however, the t-statistic associated with the test of the nullity of $\gamma$ is, in this case, largely smaller than the value obtained in regimes 2 or 3 . The productivity of infrastructure investment in the electricity sector is then slightly positive or even null if we consider uncorrected t-statistics (those that are not reported) in the last regime. In other words, when the network is completed, the use of a linear specification may lead to an overvaluation of the productivity of infrastructure in that state. This is exactly the idea developed by Fernald (1999) for the road network in the United States: the construction of the network substantially increases productivity and output, but when the construction of the network is completed, the public capital is not exceptionally productive at the margin. As was previously mentioned, these results are robust when we consider a model with three regimes and two threshold parameters. The corresponding results for the Model A $\left(q_{i t}=x_{i t}\right)$ are reported in Table A1 in Appendix A1. We obtain roughly the same estimated elasticities as reported in a model with four regimes. The only difference is that the two intermediate regimes with the highest productivities are now replaced by one regime with an estimated parameter $\gamma$ equal to 0.127 .

As far as the road sector is concerned, the productivity of infrastructure also exhibits strong network effects when the threshold variable is defined as the number of kilometers of road per worker (Table 4). As in the previous case, we observe a profile of low - high - low for productivity given the different regimes. When the paved road length that is actually available is very low, smaller than 0.36 kilometers per worker, the parameter $\gamma$ is significantly positive and greater than the value obtained in a linear specification (see Table 2); however, when the network is more important (regime 3), the value of this parameter is greater, increasing from 0.122 to 0.166 . In contrast, when the network

\footnotetext{
${ }^{7}$ This value is probably near the true elasticity value, as pointed out by Calderon and Serven (2004).
} 
is completed or nearly completed, the value of the naïve elasticity decreases to 0.129 , but is still significantly different from zero, unlike in the electricity sector. It is highly probable that in a model with more than four regimes, an extreme regime would appear with a smaller value for $\gamma$ in which some industrialised countries would figure. Finally, the last difference from the electricity sector is that an intermediate regime appears in the model with four regimes in which the estimated parameter $\gamma$ is negative and significantly different from zero. As noted by Canning (1999), the correct interpretation of the coefficient of the infrastructure variable is that it represents the output effect of increasing infrastructure capital while holding the overall physical capital constant. "That is, we measure the effect as an increase in infrastructure assuming an equal (measured of terms of the cost of investment) offsetting decrease in other forms of capital" (Canning, 1999, page 12). When this offset has a negative impact on the GDP per worker, it implies that the marginal productivity of infrastructure capital is less important than the marginal productivity of other capital. Thus, in the intermediate regime, regime 2, the marginal productivity of road infrastructure is lower than the productivity of other capital; however, this result is not robust when we consider a model with three regimes (Table A1, Appendix A1). In such a case, we still observe the low - high - low productivity profile, but the intermediate regime with a negative value of $\gamma$ disappears.

For the telecommunications sector, the results are similar and also reveal strong threshold effects. In this case, the threshold variable is defined as the number of telephones per worker. When the network is not important, infrastructure investments in the telecommunications sector have the same productivity as other forms of capital. When a network is more important, its productivity increases. In the second regime, the estimated parameter $\gamma$ is equal 0.22 , whereas it is only equal to 0.10 in a linear specification (see Table 2). In the third regime, the value of $\gamma$ falls to 0.132 as it is suggested in Fernald's analysis; however, when the telecommunications network is largely developed, with more than 126 telephones per worker, this kind of investment has another regime of high productivity. This particular regime is undoubtedly linked to the importance of the telecommunications networks in the post-industrialised countries 
included in our sample.

Finally, the results are less clear when we consider the railways sector. In this case, the high productivity regime is identified when the network is largely incomplete, with less than 0.24 kilometers of railways per worker. When the network is more important, the estimated parameter $\gamma$ becomes null or even negative. This particular evolution of railway productivity can be explained by the substitution of this means of transport with other means of transport in developing countries. After the construction of main lines between the primary urban areas in these countries, the productivity of railway investment falls (compared to investments in other means of transport) as one begins to build the secondary network between less important urban areas. Consequently, compared to the road sector, for instance, the decline in marginal productivity due to network completion in this sector is more rapidly achieved.

\section{PTR Estimates and Endogeneity}

The aforementioned results may nevertheless be subject to endogeneity bias. In order to tackle this problem and evaluate the size of the bias present in the previous subsection, we propose an instrumental variable (IV) extension of the estimation method, similar to the one performed in Fouquau et al. (2008). Let us recall that estimating the parameters $(\lambda)$ of a PTR model is done with non-linear least squares. For a given threshold parameter and a given value of the threshold variable, the model is linear and the IV estimator can be adapted in order to take into account the potential endogeneity of production factors $W_{i t}=\left(k_{i t}, h_{i t}, x_{i t}\right)$. Let us consider a simple PTR model with two regimes, as presented in (4):

$$
y_{i t}=a_{i}+\delta_{1}^{\prime} W_{i t} \mathbb{I}_{\left(q_{i t} \leq \lambda\right)}+\delta_{2}^{\prime} W_{i t} \mathbb{I}_{\left(q_{i t}>\lambda\right)}+\varepsilon_{i t} .
$$

The estimation of the parameters is carried out in two steps. First, the individual effects $a_{i}$ are eliminated by removing individual-specific means from the variables of the model. This step is standard in linear models (within transformation), but requires more careful treatment in the context of a threshold model. Let us denote $\tilde{y}_{i t}=y_{i t}-\bar{y}_{i}$, where $\bar{y}_{i}=T^{-1} \sum_{t=1}^{T} y_{i t}$. The explanatory $\left(W_{k, i t}\right)$ and instrumental $\left(z_{k, i t}\right)$ variables 
must be similarly transformed in both regimes $k, k=1,2$ :

$$
\begin{gathered}
\tilde{w}(\lambda)_{k, i t}=W_{k, i t}-\bar{W}_{k, i} \text { with } \bar{W}_{k, i}=K^{-1} \sum_{t \in K} W_{k, i t} \\
\tilde{z}(\lambda)_{k, i t}=z_{k, i t}-\bar{z}_{k, i} \text { with } \bar{z}_{k, i}=K^{-1} \sum_{t \in K} z_{k, i t},
\end{gathered}
$$

where $K$ is the sub-sample of $[1, T]$ during which regime $k$ prevails. It is straightforward to note that the transformed variables depend on the threshold $\lambda$, as it determines the prevailing regime.

Consequently, a sequential approach that alternates the estimation of $\lambda$ and the estimation of the parameter is required.

More precisely, given an initial value of $\lambda$, the production function parameters can be estimated by IV, which yields the following:

$$
\begin{aligned}
\hat{\delta}_{I V}(\lambda)= & {\left[\sum_{i=1}^{N} \sum_{t=1}^{T} \tilde{w}_{i t}^{\prime}(\lambda) \tilde{z}_{i t}(\lambda)\left(\tilde{z}_{i t}^{\prime}(\lambda) \tilde{z}_{i t}(\lambda)\right)^{-1} \tilde{z}_{i t}^{\prime}(\lambda) \tilde{w}_{i t}(\lambda)\right]^{-1} } \\
& \times\left[\sum_{i=1}^{N} \sum_{t=1}^{T} \tilde{w}_{i t}^{\prime}(\lambda) \tilde{z}_{i t}(\lambda)\left(\tilde{z}_{i t}^{\prime}(\lambda), \tilde{z}_{i t}(\lambda)\right)^{-1} \tilde{z}_{i t}^{\prime}(\lambda) \tilde{y}_{i t}\right]
\end{aligned}
$$

with $\hat{\delta}_{I V}(\lambda)=\left[\delta_{1}(\lambda), \delta_{2}(\lambda)\right]^{\prime}$. During the second phase, conditional to $\hat{\delta}_{I V}(\lambda)$, the threshold parameter $\lambda$ is estimated by NLS according to the program:

$$
\hat{\lambda}=\operatorname{ArgMin} \sum_{i=1}^{N} \sum_{t=1}^{T}\left[\tilde{y}_{i t}-\hat{\beta}_{I V}^{\prime}(\lambda) \tilde{w}_{i t}(\lambda)\right]^{2} .
$$

Table 5 reports the estimates of Model A using this procedure. The instrumental variable space is composed of one and two lagged explanatory variables. It appears that the parameters and threshold estimates are roughly identical when using or omitting the procedure above. This suggests that any endogeneity bias is negligible and does not corrupt the estimation outcomes reported in Table 4.

\section{Multi-threshold model (Model A1)}

The fact that only one infrastructure is considered to govern the threshold variable may represent a limit of model A. In model A1, we let the possibility of several infrastructures (per worker) determine the threshold function. Let us denote $x_{i t}^{(j)}$ as the 
$j^{\text {th }}$ infrastructure stock for $j=1, . ., 4$. By convention, let us define $x_{i t}^{(1)}$ as the road infrastructure variable, $x_{i t}^{(2)}$ as the telephone infrastructure variable, $x_{i t}^{(3)}$ as the electricity infrastructure variable, and $x_{i t}^{(4)}$ as the rail infrastructure variable. The threshold model $^{8}$ can now be written as:

$$
y_{i t}=a_{i}+\sum_{j=1}^{4} \delta_{1, j}^{\prime} W_{i t} \mathbb{I}_{\left\{x_{i t}^{(j)} \leq \lambda_{j}\right\}}+\sum_{j=1}^{4} \delta_{2, j}^{\prime} W_{i t} \mathbb{I}_{\left\{x_{i t}^{(j)}>\lambda_{j}\right\}}+\varepsilon_{i t},
$$

where $\delta_{z, j}=\left(\alpha_{j} \beta_{j} \gamma_{z, j}^{(1)} \gamma_{z, j}^{(2)} \gamma_{z, j}^{(3)} \gamma_{z, j}^{(4)}\right)^{\prime}$ for $z=1,2$ and $W_{i t}=\left(k_{i t} h_{i t} x_{i t}^{(1)} x_{i t}^{(2)} x_{i t}^{(3)} x_{i t}^{(4)}\right)^{\prime}$, and where $\mathbb{I}_{(.)}$is the indicator function. The error $\varepsilon_{i t}$ is assumed to be independent and identically distributed. ${ }^{9}$

The corresponding estimates are nevertheless reported in Table 6. The interpretation of the parameters $\gamma$ in this multi-threshold model is slightly different from that previously mentioned - first, because the infrastructure per worker is disaggregated. More importantly, the elasticity of production with respect to a given infrastructure $j$ for a given country $i$ cannot be read directly, but must be calculated as follows

$$
\frac{\partial y_{i t}}{\partial x_{i t}^{(j)}}=\sum_{j=1}^{4} \gamma_{1, j}^{(j)} \mathbb{I}_{\left\{x_{i t}^{(j)} \leq \lambda_{j}\right\}}+\sum_{j=1}^{4} \gamma_{2, j}^{(j)} \mathbb{I}_{\left\{x_{i t}^{(j)}>\lambda_{j}\right\}} .
$$

A comparison with the results obtained in the previous sections is difficult because, at any given time, the country can simultaneously experience a high and a low stock for a particular infrastructure. Consider the example of electricity capacity: despite the negative value of $\gamma$, it is not possible to conclude that the elasticity is necessarily negative for a given country $i$.

Also, consider the example of a country for which i) there are fewer than 1.634 kilometers of roads, ii) the electricity capacity is below 0.407 , iii) the telephone mainlines are greater than 1.715, and iv) railways exceed 0.908 kilometers in length. Elasticity would nevertheless remain positive $\left(\frac{\partial y_{i t}}{\partial x_{i t}^{(3)}}=-0.077+0.076+0.081=0.08\right)$.

Moreover, even if the elasticity were negative, that would simply indicate that the productivity of infrastructure was lower than the productivity of non-infrastructure

\footnotetext{
${ }^{8}$ For the sake of simplicity and computation time, we only consider the presence of two regimes and one transition function, including all of the infrastructure stock.

${ }^{9}$ It is possible to implement a procedure similar to the one presented in Section 5 in order to tackle the issue of potential endogeneity bias. For the sake of space and simplicity, the results are not reported in the paper, but are available upon request. The results are similar to those obtained without the procedure.
} 
capital (see Calderon and Serven, 2004, p. 98).

It follows that even if this model is more elaborate than model A, it will not be possible to draw clear a conclusion about elasticity, and the greater level of complexity will not make it more feasible to infer network effects.

\section{Threshold Models and Income Heterogeneity (Model B)}

As was previously mentioned, the threshold effects related to productivity can also be induced by the heterogeneity of the production structures of the countries of our sample. The idea is that the marginal productivity of the same infrastructure may not be equivalent for rich countries and poor countries: this heterogeneity may be the consequence of various network effects (that depend on the completion of the main infrastructure networks and not just on the completion of the infrastructure network considered), but may also exist for many other reasons (the heterogeneity of the level and quality of private capital, the heterogeneity of the economic systems, etc.). Thus, we propose to consider a threshold specification of the production function in which the threshold variable is defined by the lagged level of real GDP per worker, i.e. $q_{i t}=y_{i, t-1}$ (Model B).

It is important to note that the specification of a threshold production function, where the threshold variable is defined as the level of lagged GDP per worker, can be considered a technical solution used to circumvent the reverse causation problem. Indeed, in linear specifications, the correlation between infrastructure stocks and the productivity of private capital may reflect a causal relationship linking the changes in stock to changes in productivity. In other words, the infrastructure stocks are likely to be endogenous. This point has been extensively documented in the literature devoted to measuring the productivity of public capital (Gramlich, 1994). This concept generally leads to the use of instrumental variable methods (GMM, simultaneous equations, etc.). In our threshold specification, the correlation between GDP per worker and infrastructure stocks is conditional to the level of GDP per worker observed in the last period. Thus, if the infrastructure level is linearly linked to GDP, reverse causation 
would imply a number of regimes identical to the number of possible values of the GDP. If the number of regimes is restricted, the influence of reverse causation in each regime will be less significant than in a linear representation and may be ignored if the number of regimes is sufficiently large. A similar observation can be made for the other specifications as soon as the threshold variable is correlated with the level of lagged GDP.

As in the previous case, the first step in the Hansen estimation procedure consists of determining the number of regimes that must be adopted in the estimation of the production function. Toward that end, the model is estimated, allowing for sequentially zero, one, two, and three thresholds. For each specification, the statistics $F_{1}, F_{2}$, and $F_{3}$ and their bootstrap p-values are reported. The results of these tests for Model B are reported in Table 7. First, we can observe that whatever hypothesis is tested, the values of the F-tests are much greater than those obtained for Model A (see Table 2). This clearly indicates that the threshold effects (and the rejection of the linearity assumption) are more important when we consider per-worker income heterogeneity than when we consider the network effects of infrastructures. Secondly and consequently, for all specifications, the F-tests lead to the conclusion that there are more than 4 regimes in the production function given the level of the lagged value of real GDP per capita; however, for the same reasons as noted in the case of the Model A, we limit our analysis to a model with at most four regimes.

The estimates of the parameters of the PTR models with four regimes and the corresponding t-statistics based on standard errors corrected for heteroskedasticity are reported in Table 8. The three threshold estimates (defined based on the GDP per worker) identify four production functions and four separate groups of countries. The four regimes can be interpreted as four separate groups of countries as specified by the World Bank classification: "lower-income", "lower-middle-income", "upper-middleincome", and "high-income" countries; however, the distribution of countries in these groups is endogenous and not time-invariant because it may evolve given the level of GDP per worker. Globally, in all sectors, we can observe that the estimated parameters $\gamma$ are generally positive and significant for each group of countries. One exception is 
the case of the road sector in the last regime (high-income countries), in which this parameter becomes insignificant at the $5 \%$ level. This result is consistent with the conclusions of Fernald (1999) regarding the road sector in the United States, if we assume that when a country is in this last regime, its road network is generally achieved. More surprisingly, the values of the parameters $\gamma$ are quite similar for all of the regimes in comparison to the values obtained when the threshold variable was defined as the amount of infrastructure available per worker. This is particularly true for the telecommunications sector, wherein the parameter $\gamma$ ranges from 0.13 to 0.18 in the four groups of countries, and for the road sector, in the first three groups of countries. This result implies that the heterogeneity of infrastructure productivity is less important when we regroup the countries according to their GDP per worker than when we consider groups according to the amount of infrastructure per worker that is actually available. In other words, the heterogeneity seems to be more related to the network effects than to the level of per-capita income, even if this last measure is sometimes (but not always) a proxy for the completion of the network. The network effects seem to be more important in explaining the non-linearity of the marginal productivity of infrastructures than the threshold effects based on income heterogeneity.

\section{Conclusion}

In this paper, we provide an empirical evaluation of the threshold effects of infrastructure and public capital stocks productivity in developing countries. Our assessment is based on the estimation of various threshold panel specifications of infrastructureor public capital-augmented production functions. More precisely, we consider various specifications of a Panel Threshold Regression (PTR) model (Hansen, 1999) in which the individual parameters of the augmented production functions are divided into a small number of groups according to an observable variable. The transition mechanism for the different regimes of productivity is then determined by the level of a particular threshold variable. If the threshold variable exceeds a certain value, the production technology switches from one regime to another. Our primary results can be summarised using two main points. 
First, the relationship between output and infrastructure stocks is non-linear. More precisely, strong threshold effects can be identified as part of these relationships. This conclusion is robust to changes in the panel model used, the testing procedure applied, and the composition of the panel sample. These threshold effects are clearly identified when physical measures of the infrastructure stocks that are actually available in the country per worker are used as the threshold variable. Secondly, the productivity of infrastructure (roads, electricity, telephones, and railways) exhibits strong threshold effects that could be interpreted as network effects. In a first step, when the stock of infrastructure per worker that is actually available in a sector is very low, infrastructure investments in that sector have the same productivity as do other investments. In contrast, when the network is sufficiently developed but not complete, infrastructure investments have a level productivity that is generally much higher than the productivity of other investments. Finally, when the level of physical infrastructure stock per worker exceeds a certain value, indicating that the main network is complete, productivity rapidly decreases and infrastructure investments may not be exceptionally productive at the margin. In other words, the highest level of investment marginal productivity is reached when a network is sufficiently developed but not complete.

Therefore, these threshold effects are an argument in favour of the sectorial specialisation of public investment in infrastructure in developing countries. This specialisation may be less important in industrialised countries in which infrastructure networks are already available (water, sewer, road, rail, electricity, telecommunications, etc.). In contrast, this specialisation of infrastructure investment may be essential in developing countries where none of these main networks is near to being operational. In this case, one or two particular infrastructure networks needs to be considered a priority over all other infrastructure networks, and the majority of investment must be devoted to these priority sectors. In the poorest developing countries, water distribution and sanitation systems could be the priority, as suggested by many recent programs led by international institutions. This idea of specialisation as related to infrastructure investments might be compared to the idea of universal primary services, such as the 
universal primary education service supported by the Education for All (EFA) international commitment $(1990,2000)$. In the latter context, the goal is to ensure primary education for all children in developing countries before investing in secondary education and especially in the university system, which would benefit only a minority of the population. The mechanism is exactly the same in our network context: the highest marginal productivity of investment is reached when a network (like primary education buildings) is sufficiently developed but not complete. During this period, it would be inappropriate to begin investment in another network (like university facilities) for which the marginal productivity might be very low.

\section{References}

Ai, C. and Cassou, S.P. (1995), "A Normative Analysis of Public Capital", Applied Economics, 27, pp. 1201-1209.

Aschauer, D.A. (1989), "Is Public Expenditure Productive?", Journal of Monetary Economics 23, pp. 177-200.

Bai, J. And Perron, P. (1998), "Estimating and Testing Linear Models with Multiple Structural Changes", Econometrica, 66, pp. 47-78.

Baltagi, B.H. And Pinnoi, N. (1995), "Public Capital Stock and State Productivity Growth: Further Evidence from an Error Components Model", Empirical Economics, 20(2), pp. 351-359.

Barro, R.J. AND LeE, J.W. (2000), "International Data on Educational Attainment Updates and Implications", NBER Working Paper W7911.

Calderon, C. And Serven, L. (2004), "The Output Cost of Latin America's Infrastructure Gap", in The Limits of Stabilization, Easterly W. and Serven L. eds., The World Bank.

Calderon, C., Easterly, W. and Serven, L. (2004), "Latin America's Infrastructure in the Era of Macroeconomic Crises", in The Limits of Stabilization, Easterly W. and Serven L. eds., The World Bank. 
Canning, D. (1998), "A Database of World Infrastructure Stocks, 1950-1995", The World Bank Economic Review, 12, 529-547.

Canning, D. (1999), "Infrastructure's Contribution to Aggregate Output", The World Bank, Policy Research Working Paper Series, 2246.

Canning, D. and Bennathan, E. (2000), "The Social Rate of Return on Infrastructure Investments", The World Bank, Policy Research Working Paper Series, 2390.

Canning, D. and Pedroni, P. (1999), "Infrastructure and Long Run Economic Growth", CAER Discussion Papers, 57.

Crowder, W.J., And Himarios, D. (1997), "Balanced Growth and Public Capital: an Empirical Analysis", Applied Economics, 29, pp. 1045-1053.

Demetrias, P. and Mamuneas, T (2000), "Intertemporal Output and Employment Effects of Public Infrastructure Capital: Evidence from 12 OECD Economies", Economic Journal, 110, pp. 687-712.

Evans, P. And Karras, G. (1994), "Is Government Capital Productive? Evidence from a Panel of Seven Countries", Journal of Macroeconomics, 16(2), pp. 271-279.

Fernald, J.G. (1999), "Roads to Prosperity? Assessing the Link Between Public Capital and Productivity", The American Economic Review, 89(3), pp. 619-638.

Finn, M. (1993), "Is All Government Capital Productive?", Federal Reserve Bank of Richmond, Economic Quarterly, 79(4), pp. 53-80.

Fouquau J., Hurlin C. and Rabaud I. (2008), "The Feldstein-Horioka Puzzle: a Panel Smooth Transition Regression Approach", Economic Modelling, vol. 25(2), pp. 284-299.

Gramlich, E.M. (1994), "Infrastructure Investment: a Review Essay", Journal of Economic Literature, 32, pp. 1176-1196.

Hansen, B.E. (1996), "Inference when a Nuisance Parameter is not identified under the Null Hypothesis", Econometrica, 64, pp. 413-430.

Hansen, B.E. (1999), "Threshold Effects in Non-Dynamic panels: Estimation, Testing and Inference", Journal of Econometrics, 93, pp. 345-368. 
Holtz-Eakin, D. (1994), "Public-Sector Capital and the Productivity Puzzle", The Review of Economics and Statistics, 76, pp. 12-21.

Im, K.S., Pesaran, M.H., And Shin, Y. (2003), "Testing for Unit Roots in Heterogeneous Panels", Journal of Econometrics, 115, 1, 53-74.

Kao, C. And Chiang, M.H. (2000), "On the Estimation and Inference of a Cointegrated Regression in Panel Data", Nonstationary panels, panel cointegration, and dynamic panels, 2000, pp. 179-222.

Kamps C. (2004), The Dynamic Macroeconomic Effects of Public Capital: Theory and Evidence for OECD Countries, Springer.

Otto G.D. And Voss G.M. (1998), "Is Public Capital Provision Efficient?", Journal of Monetary Economics, 42, pp. 47-66.

Pedroni, P. (1999), "Critical Values for Cointegration Tests in Heterogeneous Panels with Multiple Regressors", Oxford Bulletin of Economics and Statistics, 61, p. 653-670.

Romp, W. And De HaAn, J. (2005), "Public Capital and Economic Growth: A critical Survey", Mimeo, University of Groningen.

Sturm, J.E., And De HaAn, J. (1995), "Is Public Expenditure Really Productive?", Economic Modelling, 12, pp. 60-72.

Summers, R., And Heston, A., (1991), "The Penn World Tables (Mark 5): An Expanded set of International Comparisons, 1950-88", Quarterly Journal of Economics, 106(2), pp. 327-368.

Swamy, P.A. (1970), "Efficient Inference in a Random Coefficient Regression Model", Econometrica, 38, pp. 311-323.

Tatom, J.A. (1991), "Public Capital and Private Sector Performance", Federal Reserve Bank of Saint-Louis Review, 73, pp. 3-17. 
Table 1. Sample Properties ${ }^{10}$

\begin{tabular}{lcccccccc}
\hline \hline & Sample & N & T & Obs. & LIC & LMI & UMI & HIC \\
\hline Paved Roads & $1965-1990$ & 50 & 26 & 1300 & 13 & 12 & 9 & 16 \\
Electricity Capacity & $1961-1995$ & 76 & 35 & 2660 & 17 & 22 & 11 & 26 \\
Number of Telephones & $1961-1990$ & 56 & 30 & 1680 & 15 & 18 & 12 & 11 \\
Railways & $1960-1992$ & 57 & 33 & 1881 & 9 & 18 & 8 & 22 \\
All Types of Infrastructure & $1965-1990$ & 24 & 26 & 624 & 5 & 9 & 5 & 5 \\
\hline \hline
\end{tabular}

Notes: The value of Obs. denotes the total number of observations in the balanced panel. The values of LIC, LMI, UMI and HIC correspond respectively to the number of Low Income Countries, Lower Middle Income countries, Upper Middle Income countries and High Income Countries included in the sample.

Table 2. Infrastructure Augmented Production Function ${ }^{11}$ Linear Panel Models with Fixed Effects and Year Dummies

\begin{tabular}{|c|c|c|c|c|c|}
\hline Within Estimates & Model 1 & Model 2 & Model 3 & Model 4 & Model 5 \\
\hline Physical Capital & $\begin{array}{l}0.473 \\
(12.4)\end{array}$ & $\begin{array}{c}0.616 \\
(44.4)\end{array}$ & $\begin{array}{l}0.529 \\
(49.0)\end{array}$ & $\begin{array}{l}0.460 \\
(31.32)\end{array}$ & $\begin{array}{c}0.576 \\
(47.7)\end{array}$ \\
\hline Human Capital & $\begin{array}{c}0.143 \\
(4.55)\end{array}$ & $\begin{array}{l}0.131 \\
(7.06)\end{array}$ & $\underset{(7.42)}{0.104}$ & $\begin{array}{l}0.109 \\
(6.28)\end{array}$ & $\begin{array}{l}0.207 \\
(10.37)\end{array}$ \\
\hline Roads & $\begin{array}{c}0.078 \\
(3.72)\end{array}$ & $\begin{array}{l}0.070 \\
(7.20)\end{array}$ & - & - & - \\
\hline Electricity & $\begin{array}{c}0.096 \\
(4.89)\end{array}$ & - & $\begin{array}{l}0.052 \\
(6.09)\end{array}$ & - & - \\
\hline Telephones & $\begin{array}{l}0.041 \\
(1.377)\end{array}$ & - & - & $\begin{array}{c}0.104 \\
(7.42)\end{array}$ & - \\
\hline Railways & $\begin{array}{c}0.063 \\
(2.41)\end{array}$ & - & - & - & $\begin{array}{l}0.192 \\
(11.19)\end{array}$ \\
\hline RSS & 5.88 & 13.6 & 41.0 & 22.1 & 24.2 \\
\hline Number of observations & 624 & 1300 & 2660 & 1680 & 1881 \\
\hline Number of countries & 24 & 50 & 76 & 56 & 57 \\
\hline
\end{tabular}

Notes: Dependent variable is log GDP per worker. All variables are measured per worker and expressed in logs. The t-statistics are in parenthesis. 
Table 3. Tests for Threshold Effects: Model A, $q_{i t}=x_{i t}{ }^{12}$

\begin{tabular}{lcccc}
\hline \hline & Roads & Electricity & Telephones & Railways \\
\hline Test for single threshold & & & & \\
$F_{1}$ & 90.2 & 112.1 & 59.5 & 128.4 \\
P-value & 0.00 & 0.00 & 0.00 & 0.00 \\
1\% Critical Values & 13.7 & 14.3 & 14.3 & 14.9 \\
$5 \%$ Critical Values & 15.3 & 15.5 & 16.8 & 16.5 \\
10\% Critical Values & 19.3 & 20.6 & 22.0 & 21.3 \\
Test for double threshold & & & & \\
$F_{2}$ & 84.7 & 74.3 & 82.6 & 122.6 \\
P-value & 0.00 & 0.00 & 0.00 & 0.00 \\
$1 \%$ Critical Values & 50.4 & 19.8 & 17.2 & 30.7 \\
$5 \%$ Critical Values & 55.2 & 22.7 & 19.2 & 36.9 \\
$10 \%$ Critical Values & 68.2 & 26.2 & 25.1 & 42.2 \\
Test for triple threshold & & & & \\
$F_{3}$ & 41.7 & 43.8 & 55.7 & 85.9 \\
P-value & 0.00 & 0.00 & 0.00 & 0.00 \\
$1 \%$ Critical Values & 13.6 & 13.6 & 13.6 & 13.2 \\
$5 \%$ Critical Values & 15.2 & 15.6 & 15.7 & 15.5 \\
$10 \%$ Critical Values & 18.0 & 21.2 & 19.2 & 18.4 \\
\hline \hline
\end{tabular}

Notes: P-values and critical values are computed from 300 simulations. F1 denotes the Fisher type statistic associated to the test of the null of no threshold against one threshold. F2 corresponds to the test one threshold against two thresholds and F3 corresponds to the test of two thresholds against three thresholds. 
Table 4. Four Regimes Panel Models ${ }^{13}$. Model A: $q_{i t}=x_{i t}$

\begin{tabular}{|c|c|c|c|c|}
\hline & Roads & Electricity & Telephones & Railways \\
\hline \multicolumn{5}{|l|}{ Regime 1: $q_{i t} \leq \lambda_{1}$} \\
\hline Physical Capital per Worker & $\begin{array}{l}0.575 \\
(32.30)\end{array}$ & $\begin{array}{l}0.519 \\
(26.78)\end{array}$ & $\begin{array}{l}0.431 \\
(21.43)\end{array}$ & $\begin{array}{l}0.613 \\
(43.70)\end{array}$ \\
\hline Human Capital per Worker & $\begin{array}{c}0.053 \\
(2.67)\end{array}$ & $\begin{array}{c}0.145 \\
(8.57)\end{array}$ & $\begin{array}{c}0.102 \\
(3.24)\end{array}$ & $\begin{array}{l}0.565 \\
(15.62)\end{array}$ \\
\hline Infrastructure per Worker & $\begin{array}{l}0.122 \\
(3.967)\end{array}$ & $\begin{array}{l}0.022 \\
(1.08)\end{array}$ & $\begin{array}{c}-0.099 \\
(-2.36)\end{array}$ & $\begin{array}{l}0.184 \\
(6.54)\end{array}$ \\
\hline \multicolumn{5}{|l|}{ Regime 2: $\lambda_{1}<q_{i t} \leq \lambda_{2}$} \\
\hline Physical Capital per Worker & $\begin{array}{l}0.403 \\
(12.34)\end{array}$ & $\begin{array}{l}0.754 \\
(22.06)\end{array}$ & $\begin{array}{l}0.389 \\
(18.48)\end{array}$ & $\begin{array}{l}0.597 \\
(42.53)\end{array}$ \\
\hline Human Capital per Worker & $\begin{array}{l}0.077 \\
(1.89)\end{array}$ & $\begin{array}{l}0.185 \\
(5.75)\end{array}$ & $\begin{array}{l}0.108 \\
(6.18)\end{array}$ & $\begin{array}{l}0.400 \\
(14.25)\end{array}$ \\
\hline Infrastructure per Worker & $\begin{array}{c}-1.682 \\
(-5.67)\end{array}$ & $\begin{array}{c}0.655 \\
(7.68)\end{array}$ & $\begin{array}{l}0.220 \\
(14.44)\end{array}$ & $\begin{array}{c}-0.096 \\
(-1.68)\end{array}$ \\
\hline \multicolumn{5}{|l|}{ Regime 3: $\lambda_{2}<q_{i t} \leq \lambda_{3}$} \\
\hline Physical Capital per Worker & $\begin{array}{l}0.567 \\
(34.93)\end{array}$ & $\begin{array}{l}0.584 \\
(38.39)\end{array}$ & $\begin{array}{l}0.465 \\
(14.51)\end{array}$ & $\begin{array}{l}0.625 \\
(42.21)\end{array}$ \\
\hline Human Capital per Worker & $\begin{array}{l}0.208 \\
(10.62)\end{array}$ & $\begin{array}{c}0.067 \\
(3.39)\end{array}$ & $\begin{array}{c}-0.168 \\
(-4.17)\end{array}$ & $\begin{array}{l}0.228 \\
(9.48)\end{array}$ \\
\hline Infrastructure per Worker & $\begin{array}{l}0.166 \\
(8.79)\end{array}$ & $\begin{array}{l}0.135 \\
(12.09)\end{array}$ & $\begin{array}{l}0.132 \\
(2.45)\end{array}$ & $\begin{array}{c}-0.157 \\
(-6.06)\end{array}$ \\
\hline \multicolumn{5}{|l|}{ Regime 4: $q_{i t}>\lambda_{3}$} \\
\hline Physical Capital per Worker & $\begin{array}{l}0.574 \\
(32.28)\end{array}$ & $\begin{array}{l}0.548 \\
(34.94)\end{array}$ & $\begin{array}{l}0.380 \\
(14.03)\end{array}$ & $\begin{array}{l}0.526 \\
(28.97)\end{array}$ \\
\hline Human Capital per Worker & $\begin{array}{l}0.104 \\
(2.53)\end{array}$ & $\begin{array}{l}0.252 \\
(7.36)\end{array}$ & $\begin{array}{c}0.126 \\
(3.27)\end{array}$ & $\begin{array}{l}0.716 \\
(12.35)\end{array}$ \\
\hline Infrastructure per Worker & $\begin{array}{l}0.129 \\
(5.03)\end{array}$ & $\underset{(2.50)}{0.041}$ & $\begin{array}{l}0.210 \\
(11.13)\end{array}$ & $\begin{array}{l}-0.014 \\
(-0.54)\end{array}$ \\
\hline \multicolumn{5}{|l|}{ Threshold Estimates } \\
\hline First Threshold $\widehat{\lambda}_{1}$ & -0.917 & -3.317 & 1.337 & -1.427 \\
\hline Second Threshold $\widehat{\lambda}_{2}$ & -0.642 & -2.954 & 4.314 & -0.882 \\
\hline Third Threshold $\widehat{\lambda}_{3}$ & 1.248 & -0.519 & 4.808 & 0.975 \\
\hline Residual Sum of Squares & 12.11 & 42.01 & 23.27 & 26.61 \\
\hline
\end{tabular}

Notes: The t-statistics in parenthesis are computed with an estimator of the covariance matrix robust to heteroskedasticity. The confidence intervals for the threshold parameters are not reported. See Appendix A1, for the confidence intervals in a model with three regimes. 
Table 5. Instrumental Variable Regressions ${ }^{14}$. Model A: $q_{i t}=x_{i t}$

\begin{tabular}{|c|c|c|c|c|}
\hline & Roads & Electricity & Telephones & Railways \\
\hline \multicolumn{5}{|l|}{ Regime 1: $q_{i t} \leq \lambda_{1}$} \\
\hline Physical Capital per Worker & $\begin{array}{l}0.608 \\
(33.91)\end{array}$ & $\begin{array}{l}0.546 \\
(27.08)\end{array}$ & $\begin{array}{l}0.442 \\
(21.44)\end{array}$ & $\begin{array}{l}0.607 \\
(40.44)\end{array}$ \\
\hline Human Capital per Worker & $\underset{(1.87)}{0.042}$ & $\begin{array}{c}0.137 \\
(7.51)\end{array}$ & $\begin{array}{c}0.117 \\
(5.04)\end{array}$ & $\begin{array}{l}0.559 \\
(15.54)\end{array}$ \\
\hline Infrastructure per Worker & $\begin{array}{c}0.130 \\
(4.02)\end{array}$ & $\begin{array}{c}0.008 \\
(0.33)\end{array}$ & $\begin{array}{c}0.128 \\
(4.72)\end{array}$ & $\begin{array}{c}0.214 \\
(6.97)\end{array}$ \\
\hline \multicolumn{5}{|l|}{ Regime 2: $\lambda_{1}<q_{i t} \leq \lambda_{2}$} \\
\hline Physical Capital per Worker & $\begin{array}{l}0.364 \\
(10.03)\end{array}$ & $\begin{array}{l}0.730 \\
(24.21)\end{array}$ & $\begin{array}{l}0.457 \\
(21.58)\end{array}$ & $\begin{array}{l}0.587 \\
(40.06)\end{array}$ \\
\hline Human Capital per Worker & $\begin{array}{l}0.368 \\
(5.64)\end{array}$ & $\begin{array}{l}0.210 \\
(5.90)\end{array}$ & $\begin{array}{l}0.057 \\
(2.17)\end{array}$ & $\begin{array}{l}0.411 \\
(13.50)\end{array}$ \\
\hline Infrastructure per Worker & $\begin{array}{c}-2.032 \\
(-6.27)\end{array}$ & $\begin{array}{l}0.524 \\
(6.85)\end{array}$ & $\begin{array}{l}0.145 \\
(7.70)\end{array}$ & $\begin{array}{c}-0.090 \\
(1.53)\end{array}$ \\
\hline \multicolumn{5}{|l|}{ Regime 3: $\lambda_{2}<q_{i t} \leq \lambda_{3}$} \\
\hline Physical Capital per Worker & $\begin{array}{l}0.596 \\
(36.19)\end{array}$ & $\begin{array}{l}0.605 \\
(39.24)\end{array}$ & $\begin{array}{l}0.527 \\
(16.66)\end{array}$ & $\begin{array}{l}0.623 \\
(47.05)\end{array}$ \\
\hline Human Capital per Worker & $\begin{array}{c}0.199 \\
(9.48)\end{array}$ & $\begin{array}{c}0.071 \\
(3.26)\end{array}$ & $\frac{-0.142}{(-3.18)}$ & $\begin{array}{l}0.221 \\
(8.78)\end{array}$ \\
\hline Infrastructure per Worker & $\begin{array}{c}0.098 \\
(4.29)\end{array}$ & $\begin{array}{c}0.111 \\
(9.23)\end{array}$ & $\begin{array}{l}0.058 \\
(1.15)\end{array}$ & $\begin{array}{c}-0.094 \\
(-3.33)\end{array}$ \\
\hline \multicolumn{5}{|l|}{ Regime 4: $q_{i t}>\lambda_{3}$} \\
\hline Physical Capital per Worker & $\begin{array}{l}0.601 \\
(31.99)\end{array}$ & $\begin{array}{l}0.569 \\
(35.18)\end{array}$ & $\begin{array}{l}0.429 \\
(15.78)\end{array}$ & $\begin{array}{l}0.537 \\
(29.15)\end{array}$ \\
\hline Human Capital per Worker & $\begin{array}{c}0.054 \\
(1.05)\end{array}$ & $\begin{array}{c}0.257 \\
(7.10)\end{array}$ & $\begin{array}{c}0.099 \\
(2.29)\end{array}$ & $\begin{array}{l}0.650 \\
(11.77)\end{array}$ \\
\hline Infrastructure per Worker & $\begin{array}{l}0.144 \\
(4.64)\end{array}$ & $\begin{array}{l}0.004 \\
(0.25)\end{array}$ & $\begin{array}{c}0.176 \\
(8.91)\end{array}$ & $\begin{array}{l}0.028 \\
(0.80)\end{array}$ \\
\hline \multicolumn{5}{|l|}{ Threshold Estimates } \\
\hline First Threshold $\widehat{\lambda}_{1}$ & -0.942 & -3.317 & 2.524 & -1.427 \\
\hline Second Threshold $\widehat{\lambda}_{2}$ & -0.676 & -2.962 & 4.326 & -0.911 \\
\hline Third Threshold $\widehat{\lambda}_{3}$ & 1.346 & -0.519 & 4.807 & 0.915 \\
\hline Residual Sum of Squares & 10.09 & 37.44 & 20.88 & 22.61 \\
\hline
\end{tabular}

Notes: For each model, the instrument set includes two lagged values of each of the explicative variables, including the corresponding infrastructure stock. The t-statistics in parenthesis are computed with an estimator of the covariance matrix robust to heteroskedasticity. The confidence intervals for the threshold parameters are not reported. See Appendix A1, for the confidence intervals in a model with three regimes. 
Table 6. Threshold Regression with all infrastructure stock as threshold variables ${ }^{15}$

\begin{tabular}{lccccc}
\hline \hline \multicolumn{1}{c}{ Threshold } & Roads & Electricity & Telephones & Railways \\
& Main regime & $x_{i t}^{(1)}>1.634$ & $x_{i t}^{(2)}>0.407$ & $x_{i t}^{(3)}>1.715$ & $x_{i t}^{(4)}>-0.9$ \\
\hline Physical Capital per Worker & 0.406 & 0.137 & 0.331 & 0.431 & 0.511 \\
& $(8.50)$ & $(2.26)$ & $(5.81)$ & $(10.63)$ & $(11.22)$ \\
Human Capital per Worker & 0.663 & 0.698 & -0.089 & 0.181 & 0.584 \\
& $(6.44)$ & $(5.64)$ & $(0.59)$ & $(5.06)$ & $(5.48)$ \\
Kilometers of Roads & 0.105 & 0.443 & 0.278 & 0.099 & 0.032 \\
& $(2.36)$ & $(5.05)$ & $(3.62)$ & $(4.91)$ & $(0.71)$ \\
Electricity Capacity & -0.077 & -0.352 & -0.333 & 0.076 & 0.081 \\
& $(-2.67)$ & $(-6.63)$ & $(4.51)$ & $(4.39)$ & $(3.35)$ \\
Telephones main lines & 0.254 & 0.636 & 0.551 & 0.013 & 0.025 \\
& $(2.59)$ & $(5.51)$ & $(4.92)$ & $(0.548)$ & $(0.25)$ \\
Kilometers of railways & 0.837 & 0.846 & 1.024 & 0.086 & 0.416 \\
& $(8.36)$ & $(8.09)$ & $(9.89)$ & $(4.54)$ & $(3.86)$ \\
& $R S S=2.880$ & $N=24$ & $T=26$ & $0 b s=624$ & - \\
\hline \hline
\end{tabular}

Notes: The t-statistics in parenthesis are computed with an estimator of the covariance matrix robust to heteroskedasticity.

Table 7. Tests for Threshold Effects: Model B, $q_{i t}=y_{i, t-1}{ }^{16}$

\begin{tabular}{lcccc}
\hline \hline & Roads & Electricity & Telephones & Railways \\
Test for single threshold $F_{1}$ & 172.4 & 324.5 & 201.0 & 495.6 \\
P-value & 0.00 & 0.00 & 0.00 & 0.00 \\
Test for double threshold $F_{2}$ & 198.9 & 319.9 & 200.4 & 363.4 \\
P-value & 0.00 & 0.00 & 0.00 & 0.00 \\
Test for triple threshold $F_{3}$ & 181.4 & 324.2 & 204.2 & 165.6 \\
P-value & 0.00 & 0.00 & 0.00 & 0.00 \\
\hline \hline
\end{tabular}

Notes: P-values are computed from 300 simulations. F1 denotes the Fisher type statistic associated to the test of the null of no threshold against one threshold. F2 corresponds to the test one threshold against two thresholds and F3 corresponds to the test of two thresholds against three thresholds. 
Table 8. Four Regimes Panel Models ${ }^{17}$. Model B: $q_{i t}=y_{i, t-1}$

\begin{tabular}{|c|c|c|c|c|}
\hline & Roads & Electricity & Telephones & Railways \\
\hline \multicolumn{5}{|l|}{ Regime 1: $q_{i t} \leq \lambda_{1}$} \\
\hline Physical Capital per Worker & $\begin{array}{l}0.500 \\
(32.9)\end{array}$ & $\begin{array}{l}0.390 \\
(29.2)\end{array}$ & $\begin{array}{l}0.319 \\
(19.1)\end{array}$ & $\begin{array}{l}0.515 \\
(40.6)\end{array}$ \\
\hline Human Capital per Worker & $\begin{array}{l}0.085 \\
(4.71)\end{array}$ & $\begin{array}{c}0.152 \\
(12.4)\end{array}$ & $\begin{array}{c}0.050 \\
(1.87)\end{array}$ & $\begin{array}{c}0.450 \\
(21.5)\end{array}$ \\
\hline Infrastructure per Worker & $\begin{array}{c}0.061 \\
(3.11)\end{array}$ & $\begin{array}{c}0.037 \\
(3.96)\end{array}$ & $\begin{array}{l}0.179 \\
(8.11)\end{array}$ & $\begin{array}{c}0.035 \\
(1.88)\end{array}$ \\
\hline \multicolumn{5}{|l|}{ Regime 2: $\lambda_{1}<q_{i t} \leq \lambda_{2}$} \\
\hline Physical Capital per Worker & $\begin{array}{c}0.526 \\
(35.1)\end{array}$ & $\begin{array}{c}0.464 \\
(35.8)\end{array}$ & $\begin{array}{l}0.355 \\
(22.6)\end{array}$ & $\begin{array}{l}0.582 \\
(46.2)\end{array}$ \\
\hline Human Capital per Worker & $\begin{array}{l}0.063 \\
(3.52)\end{array}$ & $\begin{array}{l}-0.023 \\
(-1.31)\end{array}$ & $\begin{array}{c}0.053 \\
(2.56)\end{array}$ & $\begin{array}{c}0.172 \\
(6.76)\end{array}$ \\
\hline Infrastructure per Worker & $\begin{array}{l}0.081 \\
(5.07)\end{array}$ & $\begin{array}{l}0.102 \\
(9.81)\end{array}$ & $\begin{array}{l}0.135 \\
(7.37)\end{array}$ & $\begin{array}{l}0.051 \\
(3.36)\end{array}$ \\
\hline \multicolumn{5}{|l|}{ Regime 3: $\lambda_{2}<q_{i t} \leq \lambda_{3}$} \\
\hline Physical Capital per Worker & $\begin{array}{c}0.552 \\
(37.1)\end{array}$ & $\begin{array}{c}0.475 \\
(35.8)\end{array}$ & $\begin{array}{r}0.391 \\
(22.8)\end{array}$ & $\begin{array}{c}0.630 \\
(49.8)\end{array}$ \\
\hline Human Capital per Worker & $\begin{array}{l}0.073 \\
(3.17)\end{array}$ & $\begin{array}{c}-0.033 \\
(-1.30)\end{array}$ & $\begin{array}{l}-0.068 \\
(-3.28)\end{array}$ & $\begin{array}{l}-0.027 \\
(-1.27)\end{array}$ \\
\hline Infrastructure per Worker & $\begin{array}{c}0.071 \\
(4.95)\end{array}$ & $\begin{array}{l}-0.007 \\
(-0.57)\end{array}$ & $\begin{array}{l}0.166 \\
(12.2)\end{array}$ & $\begin{array}{l}0.053 \\
(3.96)\end{array}$ \\
\hline \multicolumn{5}{|l|}{ Regime 4: $q_{i t}>\lambda_{3}$} \\
\hline Physical Capital per Worker & $\begin{array}{c}0.591 \\
(37.8)\end{array}$ & $\begin{array}{c}0.503 \\
(39.7)\end{array}$ & $\begin{array}{c}0.428 \\
(23.2)\end{array}$ & $\begin{array}{c}0.653 \\
(50.8)\end{array}$ \\
\hline Human Capital per Worker & $\begin{array}{l}-0.041 \\
(-1.68)\end{array}$ & $\begin{array}{l}-0.007 \\
(-2.76)\end{array}$ & $\begin{array}{l}-0.170 \\
(-6.29)\end{array}$ & $\begin{array}{l}-0.087 \\
(-3.38)\end{array}$ \\
\hline Infrastructure per Worker & $\begin{array}{l}0.028 \\
(1.89)\end{array}$ & $\begin{array}{c}0.114 \\
(7.80)\end{array}$ & $\begin{array}{c}0.158 \\
(11.7)\end{array}$ & $\begin{array}{l}0.042 \\
(2.95)\end{array}$ \\
\hline \multicolumn{5}{|l|}{ Threshold Estimates } \\
\hline First Threshold $\widehat{\lambda}_{1}$ & 7.838 & 8.325 & 7.833 & 8.530 \\
\hline Second Threshold $\widehat{\lambda}_{2}$ & 8.332 & 9.234 & 8.291 & 9.076 \\
\hline Third Threshold $\widehat{\lambda}_{3}$ & 9.222 & 9.674 & 9.234 & 9.602 \\
\hline Residual Sum of Squares & 8.6 & 30.2 & 17.1 & 17.2 \\
\hline
\end{tabular}

Notes: The t-statistics in parenthesis are computed with an estimator of the covariance matrix robust to heteroskedasticity. The confidence intervals for the threshold parameters are not reported. See Appendix A1, for the confidence intervals in a model with three regimes 
Table A1. Three Regimes Panel Models ${ }^{18}$. Model A: $q_{i t}=x_{i t}$

\begin{tabular}{lcccc}
\hline \hline & Roads & Electricity & Telephones & Railways \\
\hline Regime 1: $q_{i t} \leq \lambda_{1}$ & & & & \\
Physical Capital per Worker & 0.604 & 0.522 & 0.422 & 0.620 \\
& $(40.3)$ & $(36.7)$ & $(26.7)$ & $(52.9)$ \\
Human Capital per Worker & 0.078 & 0.165 & 0.099 & 0.453 \\
& $(4.21)$ & $(10.9)$ & $(5.95)$ & $(19.6)$ \\
Infrastructure per Worker & 0.138 & 0.012 & 0.207 & 0.135 \\
& $(5.34)$ & $(0.81)$ & $(14.9)$ & $(6.73)$ \\
Regime 2: $\lambda_{1}<q_{i t} \leq \lambda_{2}$ & & & & \\
Physical Capital per Worker & 0.591 & 0.584 & 0.493 & 0.629 \\
& $(42.2)$ & $(41.9)$ & $(18.5)$ & $(52.9)$ \\
Human Capital per Worker & 0.239 & 0.072 & -0.170 & 0.256 \\
Infrastructure per Worker & $(14.1)$ & $(4.69)$ & $(-4.46)$ & $(13.0)$ \\
& 0.145 & 0.127 & 0.128 & -0.139 \\
Regime 3: $q_{i t}>\lambda_{3}$ & $(8.82)$ & $(11.9)$ & $(2.53)$ & $(-5.56)$ \\
Physical Capital per Worker & & & & \\
Human Capital per Worker & 0.604 & 0.550 & 0.414 & 0.532 \\
Infrastructure per Worker & $(38.4)$ & $(39.3)$ & $(20.5)$ & $(33.2)$ \\
& $(3.48)$ & 0.254 & 0.124 & 0.731 \\
Threshold Estimates & $(4.23)$ & $(9.84)$ & $(3.47)$ & $(15.3)$ \\
First Threshold $\hat{\lambda}_{1}$ & & $(2.75)$ & 0.195 & -0.007 \\
95\% Confidence Interval & $-1.13,-0.99]$ & {$[-3.16,-2.73]$} & {$[4.78,4.84]$} & {$[-0.88,-0.82]$} \\
Second Threshold $\hat{\lambda}_{2}$ & 1.249 & -0.518 & 4.314 & 0.975 \\
95\% Confidence Interval & {$[1.10,1.38]$} & {$[-0.60,-0.13]$} & {$[4.11,4.35]$} & {$[0.91,0.99]$} \\
Residual Sum of Squares & 12.8 & 43.1 & 24.1 & 27.9 \\
\hline \hline
\end{tabular}

Notes: The t-statistics in parenthesis are computed with an estimator of the covariance matrix robust to heteroskedasticity. The confidence interval for the threshold parameters corresponds to the no rejection region of confidence level $95 \%$ associated to the likelihood ratio statistic for test on the values of the threshold parameters (see Hansen, 1999). This confidence interval can be not symetric. 
Table A2. Three Regimes Panel Models ${ }^{19}$. Model B: $q_{i t}=y_{i, t-1}$

\begin{tabular}{|c|c|c|c|c|}
\hline & Roads & Electricity & Telephones & Railways \\
\hline \multicolumn{5}{|l|}{ Regime 1: $q_{i t} \leq \lambda_{1}$} \\
\hline Physical Capital per Worker & $\begin{array}{c}0.553 \\
(38.2)\end{array}$ & $\begin{array}{l}0.451 \\
(33.9)\end{array}$ & $\begin{array}{l}0.401 \\
(24.8)\end{array}$ & $\begin{array}{c}0.575 \\
(47.7)\end{array}$ \\
\hline Human Capital per Worker & $\begin{array}{l}0.085 \\
(4.56)\end{array}$ & $\begin{array}{l}0.177 \\
(13.7)\end{array}$ & $\begin{array}{c}0.139 \\
(7.27)\end{array}$ & $\begin{array}{c}0.422 \\
(19.3)\end{array}$ \\
\hline Infrastructure per Worker & $\begin{array}{l}0.902 \\
(4.41)\end{array}$ & $\begin{array}{l}0.030 \\
(2.98)\end{array}$ & $\begin{array}{l}0.137 \\
(8.26)\end{array}$ & $\begin{array}{l}0.023 \\
(1.17)\end{array}$ \\
\hline \multicolumn{5}{|l|}{ Regime 2: $\lambda_{1}<q_{i t} \leq \lambda_{2}$} \\
\hline Physical Capital per Worker & $\begin{array}{c}0.580 \\
(41.5)\end{array}$ & $\begin{array}{c}0.526 \\
(40.8)\end{array}$ & $\begin{array}{l}0.455 \\
(25.9)\end{array}$ & $\begin{array}{l}0.641 \\
(5.3 .6)\end{array}$ \\
\hline Human Capital per Worker & $\begin{array}{l}0.084 \\
(5.74)\end{array}$ & $\begin{array}{c}-0.033 \\
(-1.78)\end{array}$ & $\begin{array}{c}-0.046 \\
(-2.13)\end{array}$ & $\begin{array}{l}0.145 \\
(5.63)\end{array}$ \\
\hline Infrastructure per Worker & $\begin{array}{c}0.118 \\
(11.3)\end{array}$ & $\begin{array}{c}0.083 \\
(7.55)\end{array}$ & $\begin{array}{l}0.141 \\
(9.91)\end{array}$ & $\begin{array}{l}0.041 \\
(2.63)\end{array}$ \\
\hline \multicolumn{5}{|l|}{ Regime 3: $q_{i t}>\lambda_{3}$} \\
\hline Physical Capital per Worker & $\begin{array}{c}0.624 \\
(40.7)\end{array}$ & $\begin{array}{c}0.556 \\
(44.6)\end{array}$ & $\begin{array}{l}0.492 \\
(26.08)\end{array}$ & $\begin{array}{c}0.686 \\
(55.6)\end{array}$ \\
\hline Human Capital per Worker & $\begin{array}{l}-0.072 \\
(-2.976)\end{array}$ & $\begin{array}{c}-0.0966 \\
(-4.13)\end{array}$ & $\begin{array}{c}-0.154 \\
(-5.38)\end{array}$ & $\begin{array}{c}-0.029 \\
(-1.37)\end{array}$ \\
\hline Infrastructure per Worker & $\begin{array}{l}0.047 \\
(3.26)\end{array}$ & $\begin{array}{l}0.091 \\
(8.10)\end{array}$ & $\begin{array}{l}0.130 \\
(9.21)\end{array}$ & $\begin{array}{c}0.047 \\
(3.54)\end{array}$ \\
\hline \multicolumn{5}{|l|}{ Threshold Estimates } \\
\hline First Threshold $\widehat{\lambda}_{1}$ & 7.838 & 8.310 & 8.289 & 8.374 \\
\hline 95\% Confidence Interval & {$[7.79,7.83]$} & {$[8.25,8.33]$} & {$[8.28,8.33]$} & {$[8.37,8.37]$} \\
\hline Second Threshold $\widehat{\lambda}_{2}$ & 9.222 & 9.234 & 9.234 & 9.076 \\
\hline 95\% Confidence Interval & {$[9.20,9.23]$} & {$[9.20,9.29]$} & {$[9.20,9.33]$} & {$[8.99,9.16]$} \\
\hline
\end{tabular}

Notes: The t-statistics in parenthesis are computed with an estimator of the covariance matrix robust to heteroskedasticity. The confidence interval for the threshold parameters corresponds to the no rejection region of confidence level $95 \%$ associated to the likelihood ratio statistic for test on the values of the threshold parameters (see Hansen, 1999). This confidence interval can be not symetric. 